\title{
Redox Chemistry of Ca-Transporter 2-Palmitoylhydroquinone in an Artificial Thin Organic Film Membrane
}

\author{
Valentin Mirčeski, ${ }^{* \dagger}$ Rubin Gulaboski, ${ }^{\ddagger}$ Ivan Bogeski, ${ }^{\S}$ and Markus Hoth ${ }^{\S}$ \\ Institute of Chemistry Faculty of Natural Sciences and Mathematics, Ss Cyril and Methodius University, \\ Skopje, Republic of Macedonia, Faculdade de Ciências, Universidade do Porto, Rua do Campo Alegre, \\ 687, 4169-007 Porto, Portugal, and Department of Physiology, Saarland University, 66421 Homburg, Germany
}

Received: December 14, 2006; In Final Form: January 26, 2007

\begin{abstract}
The redox chemistry of 2-palmitoylhydroquinone $\left(\mathrm{H}_{2} \mathrm{Q}\right)$, a recently introduced synthetic transmembrane $\mathrm{Ca}^{2+}$ transporter, was studied with cyclic and square-wave voltammetry in an artificial thin organic-film membrane sandwiched between a pyrolytic graphite electrode and an aqueous solution. The membrane has a micrometer dimension and consists of the water immiscible organic solvent nitrobenzene, which contains suitable electrolyte and $\mathrm{H}_{2} \mathrm{Q}$ as a redox active compound. The potential drop at the electrode/membrane interface is controlled by the potentiostat, whereas the potential drop at the membrane/water interface is dependent on the $\mathrm{ClO}_{4}{ }^{-}$ concentration, which is present in a large excess in both liquid phases. The redox transformation of $\mathrm{H}_{2} \mathrm{Q}$ at the electrode/membrane interface is accompanied by a corresponding ion-transfer reaction at the other side of the membrane. Proton transfer at the membrane/water interface is critical for the redox transformation of $\mathrm{H}_{2} \mathrm{Q}$ in the interior of the membrane, as a strong dependence of the voltammetric response on the $\mathrm{pH}$ of the aqueous medium was observed. $\mathrm{H}_{2} \mathrm{Q}$ undergoes two oxidation processes due to existence of two distinctive redox forms of $\mathrm{H}_{2} \mathrm{Q}$. The electrochemical mechanism can be explained with two tautomer forms of $\mathrm{H}_{2} \mathrm{Q}$ formed by migration of a proton between the 1-hydroxyl group and the adjacent carbonyl group of the palmitoyl residue. Both tautomers undergo $2 \mathrm{e} / 2 \mathrm{H}^{+}$distinctive redox transformations to form the quinone form of the studied compound. In the presence of $\mathrm{Ca}^{2+}$ in the aqueous phase, voltammetric experiments confirmed the capability of both tautomers to form 1:1 complexes with $\mathrm{Ca}^{2+}$ and to extract it into the organic membrane. Upon the oxidation of the complexes, $\mathrm{Ca}^{2+}$ is expelled back to the aqueous phase. The studied compound exhibits very similar complexing affinity toward $\mathrm{Mg}^{2+}$, implying that it is not highly selective for transmembrane $\mathrm{Ca}^{2+}$ transport.
\end{abstract}

\section{Introduction}

Organic compounds containing a benzoquinone/hydroquinone moiety are subjects of longstanding research efforts in various scientific areas due to their high relevance to biochemical systems. The most important example is ubiquinone-10 (also called coenzyme Q), which plays a critical role in the respiratory chain of mitochondria. ${ }^{1}$ Embedded in the inner mitochondria membrane, ubiquinone-10 serves as an electron shuttle and a proton pump, generating a proton and potential gradient at the inner mitochondrion membrane. The energy conserved in a form of a potential gradient is further used for synthesis of adenosinetriphosphate. The redox chemistry of the quinone/hydroquinone system is essential for antioxidant activity of various compounds including several vitamins. For instance, vitamin E, which is incorporated in cell membranes, acts as a scavenger for free radicals and reactive oxygen species. On the other hand, vitamin $\mathrm{K}$, another quinone derivative, is crucial for the blood coagulation process. Quinones/hydroquinones redox chemistry is also involved in photosynthesis in which hydroquinones operate as reducing agents mediating various processes that finally lead to oxygen release.

\footnotetext{
* To whom correspondence should be addressed. E-mail: valentin@iunona.pmf.ukim.edu.mk.

$†$ Ss Cyril and Methodius University.

† Universidade do Porto.

$\S$ Saarland University.
}

Electrochemical techniques are very well suited for characterizing quinone-like compounds. ${ }^{2-9}$ As most of the physiologically active quinones are lipophilic, electrochemical methods in nonaqueous medium have been developed.,4,8 Particularly important are biomimetic studies in which lipophilic quinone is embedded in a lipid membrane supported on the electrode surface. ${ }^{3}$ Liposomes are also suitable for membrane immobilization of lipophilic quinones. In this context, Bennett et al..$^{10}$ have recently incorporated the synthetic 2-palmitoylhydroquinone $\left(\mathrm{H}_{2} \mathrm{Q}\right)$ in a liposome membrane to build an artificial light-driven transmembrane calcium pump. Although the redox chemistry of $\mathrm{H}_{2} \mathrm{Q}$ is hardly known, these authors have utilized its redox sensitivity to analyze binding of $\mathrm{Ca}^{2+}$. According to their work, $\mathrm{H}_{2} \mathrm{Q}$ is recommended as a selective commercially available membrane transporter of $\mathrm{Ca}^{2+}$ ions. The remarkable work of Bennett et al. points out that the redox chemistry of the benzoquinone/hydroquinone system is not only important for biochemical electron-transfer chains, but it can play a crucial role in the redox sensitive transmembrane transport mechanisms of metal cations. $\mathrm{Ca}^{2+}$ is extremely relevant in this context because $\mathrm{Ca}^{2+}$ transport across membranes is one of the most important signaling mechanisms in basically all cells. ${ }^{11}$

In the current study, we directly probe the redox properties of $\mathrm{H}_{2} \mathrm{Q}$ (Figure 1) by means of thin-film electrodes in connection with voltammetric techniques. The aim of the present work is to provide an insight into the redox chemistry of this important 
<smiles>O=C(c1ccccc1)c1cc(O)ccc1O</smiles>

Figure 1. Molecular structure of 2-palmitoylhydroquinone.

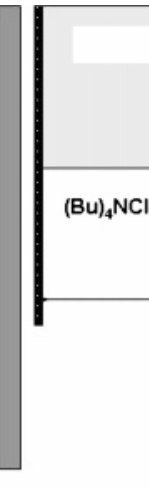

Edge Plane Pyrolytic Graphite Electrode

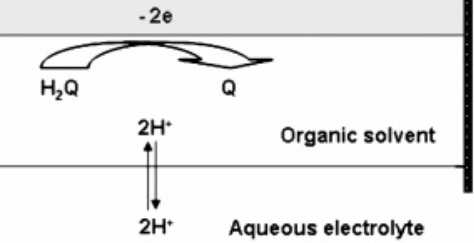

Aueous electrolyte

Reference electrode

Counter electrode

Figure 2. Schematic representation of the thin-film electrode assembly consisting of a membrane of an organic solvent imposed on the graphite electrode surface. The membrane contains $\mathrm{H}_{2} \mathrm{Q}$ as a redox probe and a suitable electrolyte. The thin-film electrode is immersed into aqueousbuffered solution containing a common ion with the organic electrolyte. The modified electrode is used in a conventional three-electrode configuration.

lipophilic synthetic compound embedded in an artificial membrane, as well as to probe its capabilities to facilitate the transport of $\mathrm{Ca}^{2+}, \mathrm{Mg}^{2+}$, and $\mathrm{Ba}^{2+}$ across water/organic-film membrane interface.

The experimental assembly used (Figure 2) consists of a micrometer dimension organic-film membrane sandwiched between a highly oriented pirolytic graphite electrode and an aqueous electrolyte solution. The organic-film membrane consists of a water immiscible nitrobenzene (NB) solution containing a suitable electrolyte and $\mathrm{H}_{2} \mathrm{Q}$ as a redox active compound. The membrane forms a stable liquid interface with the aqueous phase, whereas its high electrical conductance and partial water content permit ionic and protolitic reactions to proceed at an appreciable rate in the membrane interior. $\mathrm{H}_{2} \mathrm{Q}$, which is present at millimolar concentration levels, undergoes redox transformation at the electrode/membrane interface, the redox transformation being driven by the potential gradient controlled by potentiostat. The potential drop at the membrane/water interface is dependent on the distribution of $\mathrm{ClO}_{4}{ }^{-}$, which is present in large excess in both liquid phases. The electron transfer at the one side of the membrane is accompanied by a simultaneous charge compensating ion-transfer reaction at the other side of the membrane. The overall electrochemical process couples the electron with the ion-transfer reaction proceeding at different membrane sides. Thus, the experimental system used, though quite simple, provides an insight into the mechanistic, energetic, and kinetic features of the coupled electron-ion-transfer reaction of biochemical significance. ${ }^{12-18}$

The electrochemical experiments have been conducted with conventional cyclic $(\mathrm{CV})^{19}$ and square-wave voltammetry $(\mathrm{SWV})^{20}$ techniques. The latter technique is one of the most advanced voltammetric methods unifying the advantages of CV and pulse voltammetric techniques. In the course of a SW voltammetric experiment, the potential is repeatedly changed to an oxidative and reductive mode in a form of square-shaped potential pulses. The time interval in which a redox reaction is completed in both oxidation and reduction directions ranges

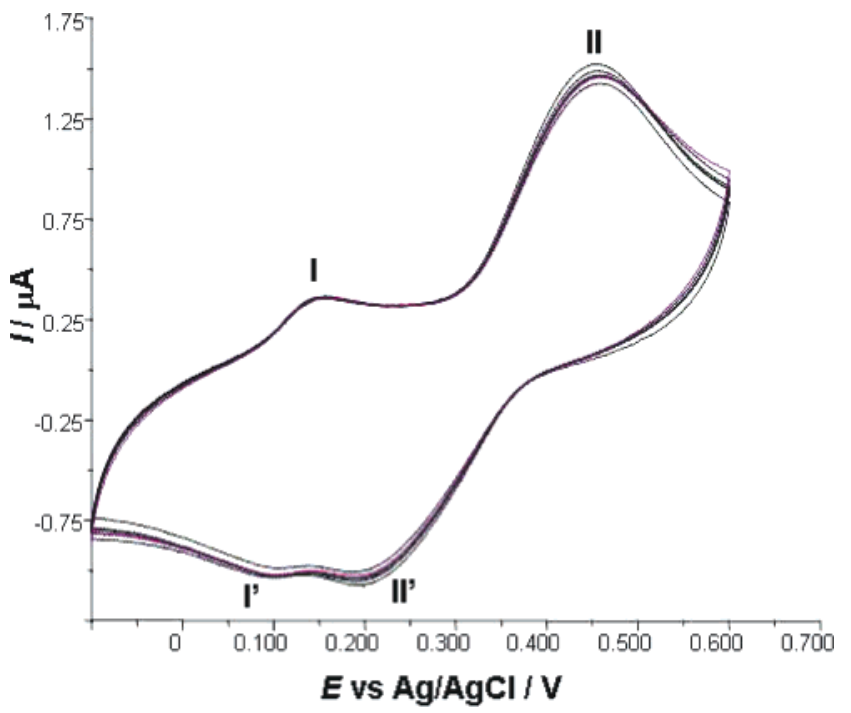

Figure 3. Consecutive cyclic voltammograms recorded at the thinfilm electrode containing $10 \mathrm{~mol} / \mathrm{L} \mathrm{H}_{2} \mathrm{Q}$ in contact with $0.1 \mathrm{~mol} / \mathrm{L}$ $\mathrm{KClO}_{4}$ aqueous solution buffered with a $0.1 \mathrm{~mol} / \mathrm{L}$ phosphate buffer at $\mathrm{pH}$ of 5.0. Besides the redox probe, the organic phase contains 0.1 $\mathrm{mol} / \mathrm{L}$ tetrabuthylammonium perchlorate $\left(\mathrm{Bu}_{4} \mathrm{NClO}_{4}\right)$ as an organic electrolyte. Scan rate was $v=5 \mathrm{mV} / \mathrm{s}$.

from 1 to $100 \mathrm{~ms}$, thus providing intrinsic information on the charge-transfer mechanism and kinetics of the studied electrochemical reaction.

\section{Materials and Methods}

$\mathrm{H}_{2} \mathrm{Q}$ (99\% purity) was purchased from MERCK and was used without further purification. All other chemicals were of highest purity. $\mathrm{H}_{2} \mathrm{Q}$ was dissolved in a water-saturated $\mathrm{NB}$ at a concentration of $10 \mathrm{mmol} / \mathrm{L}$. Besides the redox compound, NB contained $0.1 \mathrm{~mol} / \mathrm{L}$ tetrabuthylammonium perchlorate $\left(\mathrm{Bu}_{4} \mathrm{NClO}_{4}\right)$ as an organic electrolyte. A disk electrode $(0.32$ $\mathrm{cm}^{2}$ ) of edge plane pyrolytic graphite (EPGE) was used as a working electrode. $\mathrm{An} \mathrm{Ag} / \mathrm{AgCl}(3 \mathrm{M} \mathrm{KCl})$ electrode was used as a reference and a platinum wire as an auxiliary electrode. The modification of the working electrode and its pretreatment is described elsewhere. ${ }^{17} \mathrm{NB}$ solution $(0.5 \mu \mathrm{L})$ was deposited on the graphite electrode with the help of a micropipette; the organic solution spreads spontaneously over the electrode surface forming a stable film. The modified electrode was immersed into aqueous buffer solutions composed of $0.1 \mathrm{~mol} / \mathrm{L}$ $\mathrm{Na}_{2} \mathrm{HPO}_{4}, 0.1 \mathrm{~mol} / \mathrm{L} \mathrm{NaH} \mathrm{PO}_{4}$, and an appropriate amount of citric acid. Besides the buffer, the aqueous phase contained 0.1 $\mathrm{mol} / \mathrm{L} \mathrm{KClO}_{4}$ as a supporting electrolyte. NB-saturated water (Millipore Q) was used for preparing all aqueous solutions.

In addition, electrochemistry of microcrystals of $\mathrm{H}_{2} \mathrm{Q}$ immobilized on the electrode surface was also studied in a direct contact with the aqueous phase. To achieve this, $0.5 \mu \mathrm{L}$ of a dichloroethane solution of $\mathrm{H}_{2} \mathrm{Q}(c=10 \mathrm{mmol} / \mathrm{L})$ was imposed on the electrode surface. After evaporation of the solvent for a few minutes, the surface of EPGE had been modified with immobilized microcrystals of $\mathrm{H}_{2} \mathrm{Q}$.

SW and cyclic voltammograms were recorded using $\mu$ Autolab Model III equipment (Eco-Chemie, Utrecht, Netherlands). All experiments were performed at room temperature.

\section{Results}

3.1. Redox Behavior of $\mathrm{H}_{2} \mathrm{Q}$ in the Organic-Film Membrane in Contact with $\mathrm{Ca}^{2+}$-Free Aqueous Solutions. Shown in Figure 3 are typical $\mathrm{CVs}$ of $\mathrm{H}_{2} \mathrm{Q}$ embedded in a $\mathrm{NB}$ 


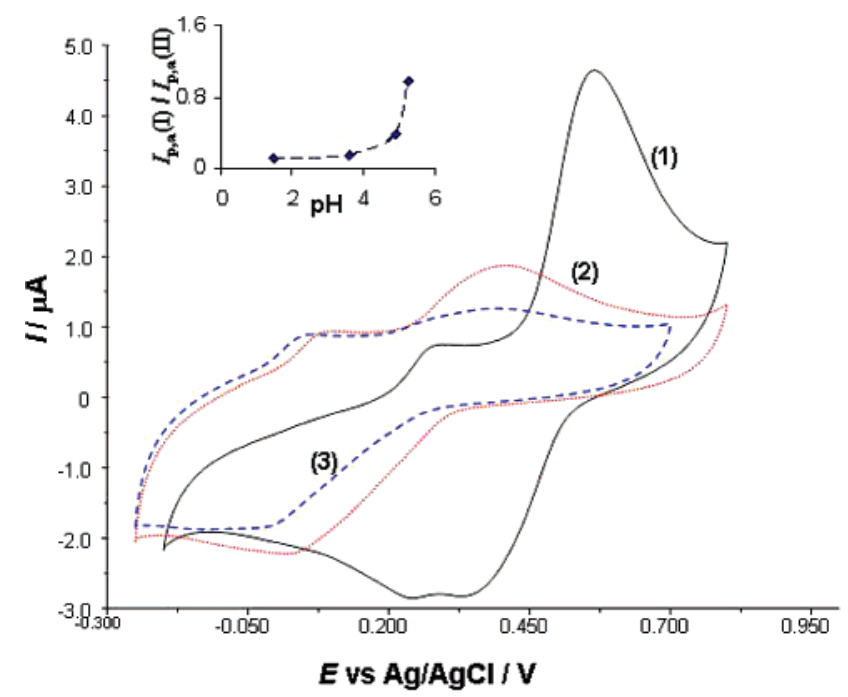

Figure 4. Cyclic voltammograms at thin-film electrode recorded in contact with aqueous medium at $\mathrm{pH} 1.5$ (1), 4.9 (2) and 5.3 (3). Scan rate was $10 \mathrm{mV} / \mathrm{s}$. The other conditions are the same as for Figure 3 . The inset shows the dependence of the anodic peak current ratio $I_{\mathrm{p}, \mathrm{a}}(\mathrm{I}) / I_{\mathrm{p}, \mathrm{a}}(\mathrm{II})$ on $\mathrm{pH}$.

membrane in contact with an aqueous buffer at $\mathrm{pH}$ of 5 , recorded by consecutive cycling of the potential. The features of repetitive CVs reflect the stability of the membrane and the chemical reversibility of the redox transformations of $\mathrm{H}_{2} \mathrm{Q}$. CV response of $\mathrm{H}_{2} \mathrm{Q}$ features two distinctive peak-pairs (i.e., $\mathrm{I}-\mathrm{I}^{\prime}$ and II- II'). The relative heights and positions of the voltammetric peaks are strongly sensitive to the $\mathrm{pH}$, which was varied from 1 to 7 ; at higher $\mathrm{pH}$ the voltammetric parameters of the $\mathrm{CV}$ response were hardly measurable. Figure 4 shows typical CVs recorded at $v=10 \mathrm{mV} / \mathrm{s}$ at different $\mathrm{pH}$. The midpeak potentials $\left(E_{\mathrm{p}, \mathrm{m}}=\left(E_{\mathrm{p}, \mathrm{a}}-E_{\mathrm{p}, \mathrm{c}}\right) / 2\right.$ in which $E_{\mathrm{p}, \mathrm{a}}$ and $E_{\mathrm{p}, \mathrm{c}}$ correspond to the peak potential of the anodic and cathodic peak, respectively) of both redox processes shift linearly with $\mathrm{pH}$ (data not shown) with a slope of about $-60 \mathrm{mV} / \mathrm{pH}$, indicating that the two oxidation processes of $\mathrm{H}_{2} \mathrm{Q}$ are accompanied by an expulsion of protons from the membrane into the aqueous phase. The inset of Figure 4 presents the variation of the anodic peak current ratio $I_{\mathrm{p}, \mathrm{a}}(\mathrm{I}) / I_{\mathrm{p}, \mathrm{a}}(\mathrm{II})$, which was increased from 0.11 to 0.97 if the $\mathrm{pH}$ was increased from 1.5 to 5 . Higher $\mathrm{pH}$ increased the amplitude of first oxidation peak at the expense of the second one. Moreover, an increase of $\mathrm{pH}$ caused a strong shift of the cathodic peak II' toward more negative potentials. The voltammetric curve 2 in Figure 4 shows that the latter cathodic peak appears only as a shoulder of the cathodic peak I', whereas at pH 5.3 (curve 3 ) the cathodic peak II' is completely merged into the cathodic peak I'.

The peak potential separation of the peak-couple $\mathrm{I}-\mathrm{I}^{\prime}$ depended mainly on the scan rate. At a low scan rate of $v=1$ $\mathrm{mV} / \mathrm{s}$, the peak potential separation is 40 and $42 \mathrm{mV}$ for an aqueous medium at $\mathrm{pH} 5$ and 1.5 , respectively, being close to the theoretical value of $30 \mathrm{mV}$ for a reversible two-electron process. ${ }^{19}$ An increase of the scan rate up to $v=100 \mathrm{mV} / \mathrm{s}$ was followed by a permanent increase of the potential separation of the couple $I-I^{\prime}$, which is typical for a quasireversible electrode process. At $\mathrm{pH} \mathrm{5,} \mathrm{the} \mathrm{potential} \mathrm{separation} \mathrm{at} v=0$ $\mathrm{mV} / \mathrm{s}$, found by extrapolation of the dependence $E_{\mathrm{p}}$ versus $v$ for the peaks I and $\mathrm{I}^{\prime}$, is about $38 \mathrm{mV}$ (see the inset of Figure 5 a). On the other hand, the voltammetric behavior of the peak couple II-II' is considerably different. For the same voltammograms mentioned above, recorded at $\mathrm{pH} 1.5$ and 5 at $v=1$ $\mathrm{mV} / \mathrm{s}$, the peak potential separation for the couple II-II' is 101 and $128 \mathrm{mV}$, respectively. The peak potential separation of the couple II-II' increased more rapidly by increasing the scan rate compared to the couple $\mathrm{I}-\mathrm{I}^{\prime}$. Moreover, the peak potential separation increased significantly by increasing of $\mathrm{pH}$ of the medium (see Figure 5), which was much less pronounced for the couple $\mathrm{I}-\mathrm{I}^{\prime}$.

The evolution of the CVs as a function of the scan rate at a constant $\mathrm{pH}$ is shown in Figure 5. The inset of Figure 5b shows the variation of the peak current ratio $I_{\mathrm{p}, \mathrm{a}}(\mathrm{I}) / I_{\mathrm{p}, \mathrm{a}}(\mathrm{II})$ by increasing the scan rate. In addition, the cathodic peak II' strongly shifted toward negative potentials by increasing the scan rate. Indeed, this peak disappeared, or it was merged into the cathodic peak $\mathrm{I}^{\prime}$, for a scan rate $v \geq 100 \mathrm{mV} / \mathrm{s}$ (Figure 5d). Obviously the effect of the scan rate on the peak current ratio and the position of the cathodic peak $\mathrm{II}^{\prime}$ is equivalent to that of $\mathrm{pH}$, shown in Figure 4. The inset of Figure $5 \mathrm{c}$ shows the variation of the scan rate-normalized anodic peak current, $I_{\mathrm{p}, \mathrm{a}} / v$ versus $v$, for both anodic peaks I and II. The ratio $I_{\mathrm{p}} / v$ for anodic peak II decreases severely by increasing the scan rate, indicating a CE mechanism in which the electrode reaction is gated by a slow-preceding chemical step. ${ }^{19}$

The response of $\mathrm{H}_{2} \mathrm{Q}$ in the $\mathrm{NB}$ membrane under conditions of SWV consisted of two well-defined and separated oxidative net peaks (Figure 6A). At a constant $\mathrm{pH}$, the relative heights of the two peaks varied proportionally with the number of repetitive SW voltammograms recorded with a single thin-film electrode. The evolution of consecutive SW voltammograms reveals that the magnitude of the peak I increases in proportion with the time of subsequent SW potential cycling, whereas peak II proportionally diminishes (Figure 6A). The sum of both peaks is virtually constant for each voltammogram, while a steadystate response is reached after $5 \mathrm{~min}$ of potential cycling (see the inset of Figure 6A). Interestingly, without potential cycling the peak heights were insensitive to the contact time of the electrode with the aqueous electrolyte (Figure 6B). If the resting potential was kept at the value between the peaks I and II (i.e., $E_{\text {rest }}=0.15 \mathrm{~V}$ ), the duration of the resting period had no effect on the magnitude of the peak II, indicating that the electroactive reactant for the process II is not generated during the electrode process I (Figure 7).

To probe the redox chemistry of $\mathrm{H}_{2} \mathrm{Q}$ in direct contact with the aqueous phase, microcrystals of $\mathrm{H}_{2} \mathrm{Q}$ were immobilized on the EPGE, applying the procedure described in Section 2. The response of $\mathrm{H}_{2} \mathrm{Q}$ microcrystals immobilized on the electrode surface consisted of two well-separated SW peaks (Figure 8A). The position of the response was strongly sensitive to the $\mathrm{pH}$ of the aqueous phase. Moreover, the ratio $I_{\mathrm{p}}(\mathrm{I}) / I_{\mathrm{p}}(\mathrm{II})$ increased by increasing $\mathrm{pH}$, as well as by repetitive cycling of the potential in the SWV experiment. Overall, the intrinsic voltammetric behavior was similar to that observed in a thin-film experiment.

The variation of the frequency provides further insight into the electrode mechanisms of the two processes. As shown in Figure $8 \mathrm{~B}$, the net peak current I increased nonlinearly with the frequency, which is typical behavior for quasireversible processes of an immobilized reactant ${ }^{20}$ or a reactant embedded in a thin-film membrane. ${ }^{21}$ On the contrary, the peak II strongly diminished as the critical time of the voltammetric experiment was decreased (i.e., by increasing the frequency). The diminishing of the peak II is typical for both the microcrystal-modified electrode and for the thin-film electrode assembly. This analysis strongly suggests a CE reaction scheme for the process II, which agrees with the results observed with $\mathrm{CV}$ (cf. Figure 5c). It should be noted that the decrease of the peak II is more 

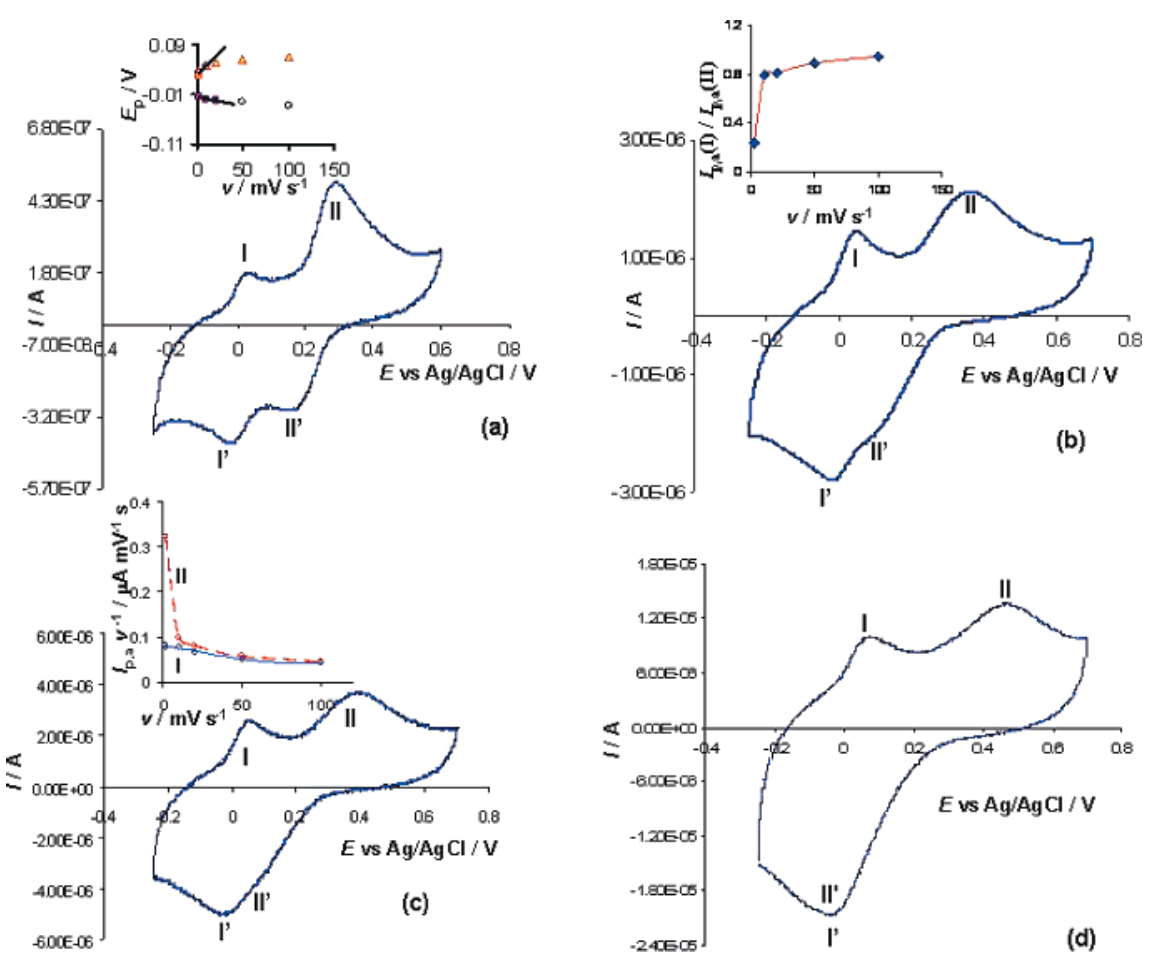

Figure 5. Effect of the scan rate on the shape of the cyclic voltammograms recorded at thin-film electrode in contact with an aqueous medium at $\mathrm{pH}$ 5. The scan rate was $v=1$ (a), 10 (b), 20 (c), and $100 \mathrm{mV} / \mathrm{s}$ (d). The inset of (a) shows the variation of the peak potential with the scan rate for the peaks I and $I^{\prime}$. The inset of (b) shows the variation of the anodic peak current ratio $I_{\mathrm{p}, \mathrm{a}}(\mathrm{I}) / I_{\mathrm{p}, \mathrm{a}}(\mathrm{II})$ on the scan rate. The inset of (c) shows the variation of the ratio $I_{\mathrm{p}, \mathrm{a}} / v$ on the scan rate for the peaks I and II.

pronounced under conditions of SWV than in $\mathrm{CV}$, as the former is the much faster voltammetric method.

The kinetics of the electrochemical process I were further analyzed by exploiting the "quasireversible maximum" (QRM) phenomenon, a feature typical for surface processes ${ }^{20}$ and processes in thin-film membranes. ${ }^{18,21,22}$ The theoretical background of this methodology has been elaborated in a series of previous publications. ${ }^{16,18,21,22}$ The theory predicts a parabolic dependence of the ratio $I_{\mathrm{p}} f^{-0.5}$ versus $f$ (or alternatively, log(f)) with the maximum of the parabola being located within the quasireversible kinetic region of the studied redox reaction in the membrane. The exact position of the QRM is associated with a certain critical frequency $\left(f_{\max }\right)$ upon which the rate of the redox transformation is synchronized with the frequency thus producing a maximum ratio $I_{\mathrm{p}} f_{\max }{ }^{-0.5}$. The faster the kinetics of the studied reaction is, the higher the critical frequency is. For complex processes in a thin-film membrane in which the electron transfer at one side is coupled with the ion transfer at the other side of the membrane, the features of the QRM allow the detection of the of the rate-limiting step of the overall electrochemical reaction. For instance, when the ion transfer is the rate decisive step, the position of the QRM shifts consistently toward higher critical frequencies by increasing the concentration of the transferring ion in the aqueous phase. ${ }^{16,22}$

When the electrode was modified with microcrystals of $\mathrm{H}_{2} \mathrm{Q}$, a well-formed QRM was observed with a position of the maximum being dependent on $\mathrm{pH}$ of the medium. Decreasing $\mathrm{pH}$ caused the maximum to shift toward higher frequencies, the critical values being $f_{\max }=60$ and $320 \mathrm{~Hz}$ for $\mathrm{pH} 3.9$ and 1.5 , respectively. An analogous behavior of the QRM was observed for the experiment in a thin membrane in which the corresponding critical frequencies are $f_{\max }=30$ and $280 \mathrm{~Hz}$ for $\mathrm{pH} 3.9$ and 1.5, respectively. It should be noted that in the thin-film experiment the redox transformation in the membrane must be accompanied by a corresponding ion-transfer reaction across the water/membrane interface to maintain the charge neutrality of the membrane. To analyze the influence of the ion-transfer reaction on the overall electrochemical process in the membrane, kinetic measurements have been conducted by systematic alteration of the potential drop at the water/membrane interface. These experiments have been performed by adjusting the concentration of $\mathrm{ClO}_{4}{ }^{-}$in both liquid phases, which is the main potential-controlling ion present in a large excess in both liquid phases. Figure 9 shows the evolution of the QRM by increasing the $\mathrm{ClO}_{4}{ }^{-}$concentration in the aqueous phase, which is manifested as an acceleration of the overall redox transformation within the membrane.

3.2. Redox Behavior of $\mathrm{H}_{2} \mathrm{Q}$ in Aqueous Solutions Containing $\mathrm{Ca}^{2+}$ Ions. $\mathrm{Ca}^{2+}$, as a double-charged ion, exists as a strongly hydrated ion in an aqueous medium. In a medium with $\mathrm{pH}>7$, hydroxo-complexes of $\mathrm{Ca}^{2+}$ are also encountered. The hydrophobicity of $\mathrm{Ca}^{2+}$ is so high that its direct transfer from aqueous to nonaqueous medium cannot be achieved with the contemporary electrochemical techniques. For these reasons, the transfer of $\mathrm{Ca}^{2+}$ ions across artificial or living cell membranes proceeds according to a facilitated ion-transfer mechanism enabled by lipophilic-complexing agents embedded in the membrane. On the basis of this mechanism, $\mathrm{H}_{2} \mathrm{Q}$ has been exploited as a $\mathrm{Ca}^{2+}$ transporter through liposome membrane. ${ }^{10}$

Figure 10A depicts several SW voltammograms recorded after the thin-film electrode was immersed in a buffer solution containing various concentrations of $\mathrm{Ca}^{2+}$ ions. As can be inferred from Figure 10A, the redox chemistry of $\mathrm{H}_{2} \mathrm{Q}$ in the membrane is sensitive to the $\mathrm{Ca}^{2+}$ content in the aqueous phase. An increase of the $\mathrm{Ca}^{2+}$ concentration causes a proportional and equivalent shift of both voltammetric peaks toward more positive potentials. The dependence of the net peak potentials on the logarithm of the $\mathrm{Ca}^{2+}$ concentration is linear with an identical slope for both peaks of about $36 \mathrm{mV} / \log \left[\mathrm{Ca}^{2+}\right]$ (Figure 10B). Besides the position, the $\mathrm{Ca}^{2+}$ concentration significantly 

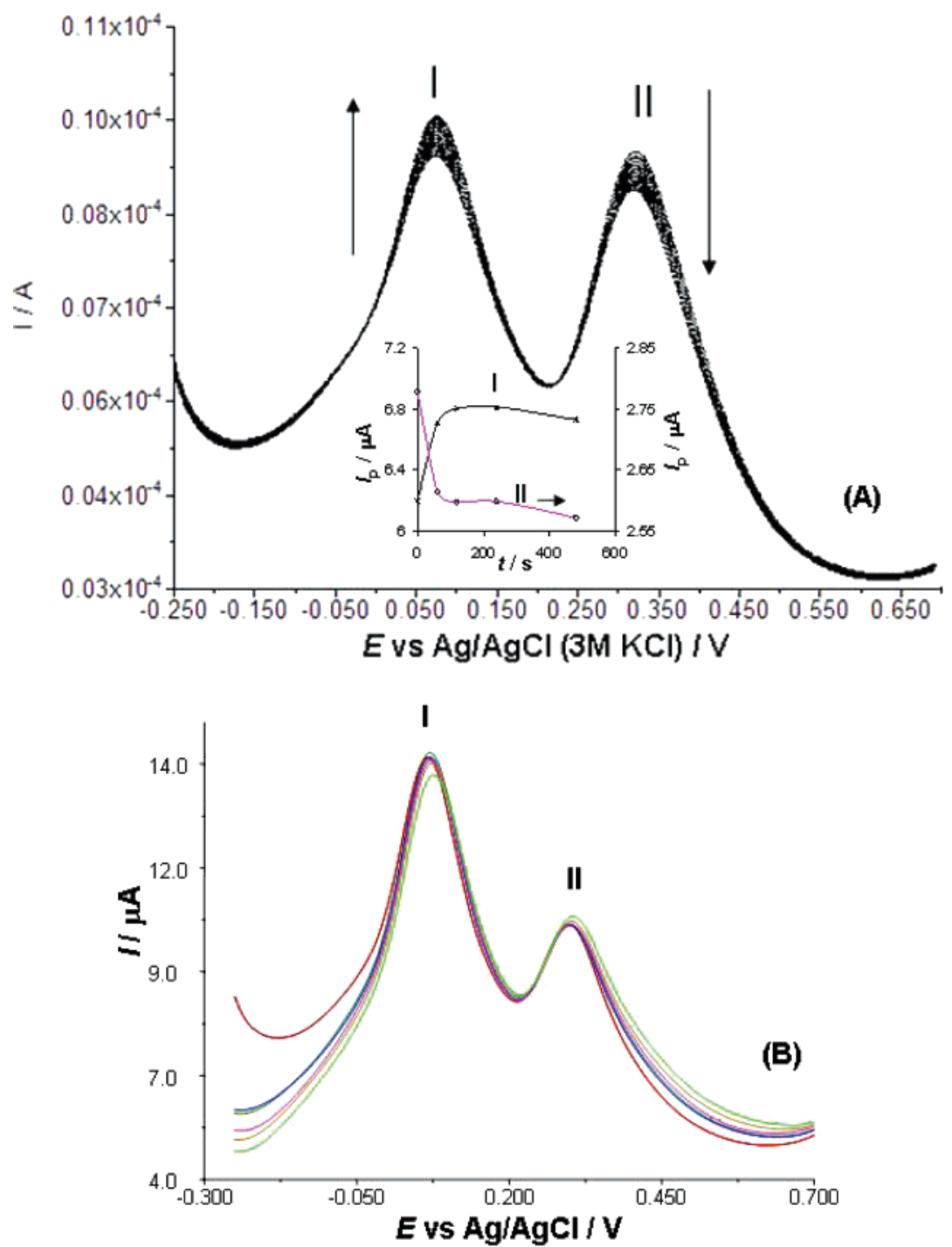

Figure 6. (A) Consecutive net SW voltammograms recorded at the thin-film electrode in contact with aqueous medium at $\mathrm{pH} 3.9$. The inset shows the dependence of the net peak currents of peaks (I) and (II) on the time of potential cycling. (B) Effect of the resting time of the electrode in the aqueous electrolyte, varied from 0 to $1000 \mathrm{~s}$ with a step of $100 \mathrm{~s}$. The resting potential was $-0.25 \mathrm{~V}$. Each voltammogram was recorded by imposing a new film on the electrode surface. The parameters of the potential modulation were: SW frequency $f=8 \mathrm{~Hz}, \mathrm{SW}$ amplitude $E_{\mathrm{sw}}=50$ $\mathrm{mV}$, and scan increment $\mathrm{d} E=1 \mathrm{mV}$. The other conditions are the same as for Figure 3 .

affected the magnitude of the voltammetric peaks. Enhancing the $\mathrm{Ca}^{2+}$ concentration resulted in a consistent enlarging of the peak I. At the same time, the peak II proportionally diminishes. It is very important to emphasize that the $\mathrm{pH}$ dependence of both processes is significantly altered in the presence of $\mathrm{Ca}^{2+}$. For $9 \mathrm{mM} \mathrm{Ca}^{2+}$, the linear dependence of $E_{\mathrm{p}}$ versus $\mathrm{pH}$ had a slope of $-34 \mathrm{mV} / \mathrm{pH}$ for both redox processes. The corresponding dependence in the absence of $\mathrm{Ca}^{2+}$ was $-60 \mathrm{mV} / \mathrm{pH}$.

At a constant $\mathrm{pH}$ and $\mathrm{Ca}^{2+}$ concentration, the relative peak heights vary strongly with the contact time of the membrane with the aqueous phase with or without repetitive cycling of the SW potential modulation. This effect is clearly illustrated by the repetitive SW voltammograms shown in Figure 11A. The first peak strongly increased over time at the expense of the second one. After a period of $15 \mathrm{~min}$, the second peak almost completely vanished. Note that similar behavior was observed in a $\mathrm{Ca}^{2+}$-free aqueous solution (Figure 6A). However, in the absence $\mathrm{Ca}^{2+}$ ions, the overall effect was less pronounced, and the repetitive potential cycling led to a steady-state voltammogram without a complete vanishing of the peak II. Figure 11B shows the evolution of SW voltammograms with the incubation time of the electrode in a separate aqueous solution containing $0.1 \mathrm{~mol} / \mathrm{L} \mathrm{Ca}^{2+}$ ions. After the incubation period, the electrode was transferred into a Ca-free buffer solution to record the voltammogram. Again, the first peak increased with time at the expense of the second one, which almost vanished after an incubation period of $45 \mathrm{~min}$. This is a unique phenomenon related to the incubation in a $\mathrm{Ca}^{2+}$-containing solution (compare Figures $6 \mathrm{~B}$ and 11B).

Kinetic measurements carried out with QRM referring to the peak I showed that the apparent kinetics of the electrochemical process is independent of the content of $\mathrm{Ca}^{2+}$ ions in the aqueous phase. The binding and transferring abilities of $\mathrm{H}_{2} \mathrm{Q}$ toward $\mathrm{Mg}^{2+}$ and $\mathrm{Ba}^{2+}$ ions were also tested. Figure 12 shows the evolution of the SW voltammograms at various concentrations of $\mathrm{Mg}^{2+}$ and $\mathrm{Ba}^{2+}$ ions. The overall voltammetric behavior in the presence of $\mathrm{Mg}^{2+}$ (Figure 12A) is equivalent to that in the presence of $\mathrm{Ca}^{2+}$ ions, revealing that $\mathrm{H}_{2} \mathrm{Q}$ does not discriminate between $\mathrm{Ca}^{2+}$ and $\mathrm{Mg}^{2+}$ ions. On the contrary, the voltammetric response is insensitive to $\mathrm{Ba}^{2+}$ (Figure 12B), showing the absence of complexing ability of $\mathrm{H}_{2} \mathrm{Q}$ toward these ions. 


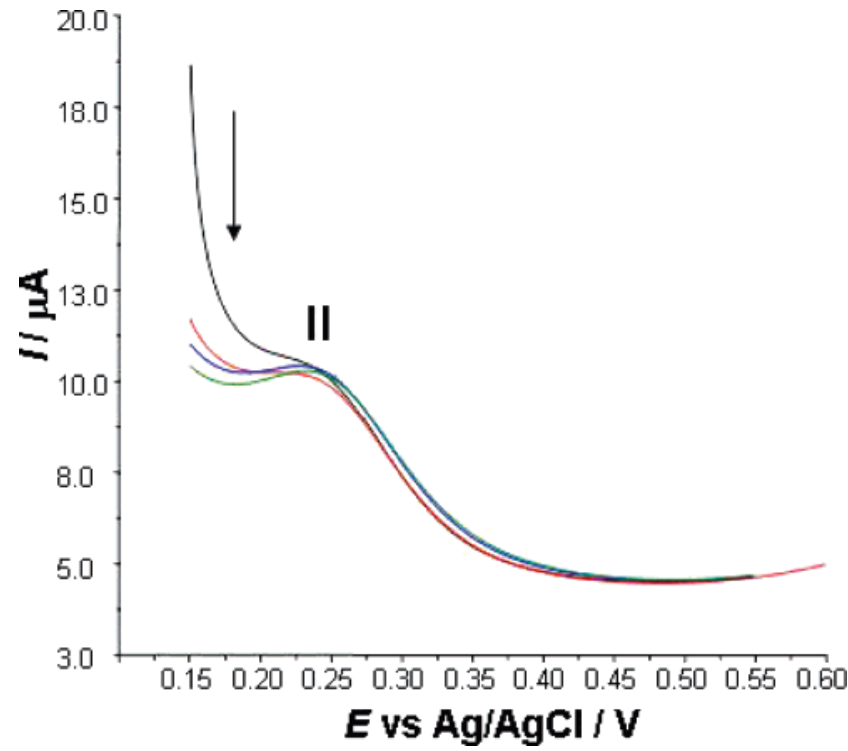

Figure 7. Effect of the resting potential on the net SW peak II, recorded with a thin-film electrode in contact with an aqueous solution at $\mathrm{pH} 5$. The resting potential was $0.15 \mathrm{~V}$. The time increases in the direction of the arrow from $0,20,50$, to $100 \mathrm{~s}$. The other conditions are the same as for Figure 3. The parameters of the potential modulation are the same as for Figure 6.

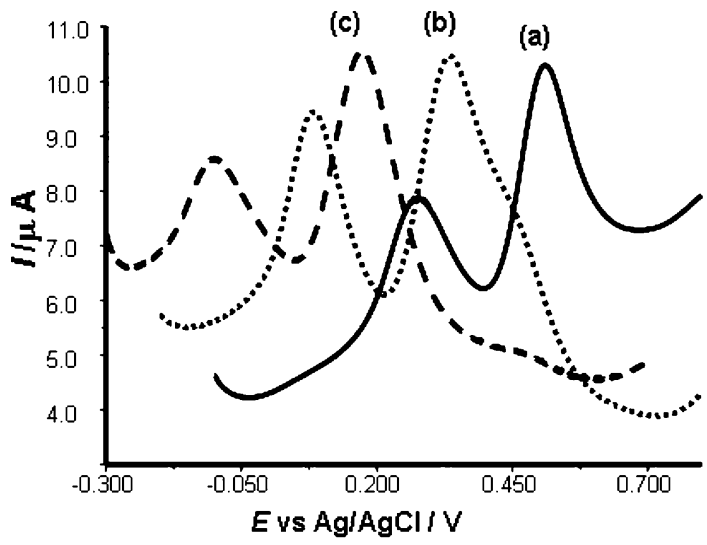

(A)

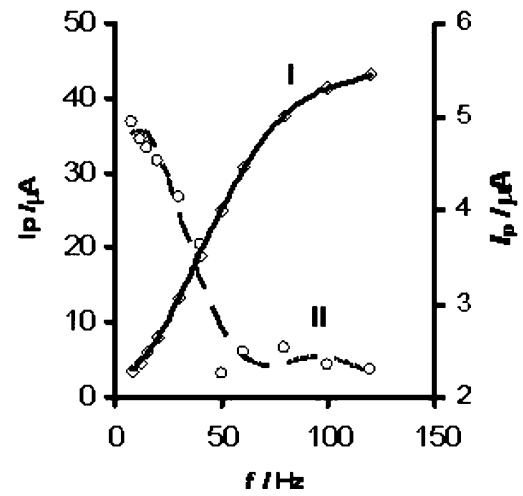

(B)

Figure 8. (A) SW voltammetric responses of immobilized microcrystals of $\mathrm{H}_{2} \mathrm{Q}$ recorded in direct contact with the aqueous phase at pH 1 (a), 3.9 (b), and 7 (c). The parameters of the potential modulation were the same as for Figure 6. (B) Dependence of the net SW peaks I and II on the frequency of the potential modulation for $\mathrm{pH} 3.9$.

\section{Discussion}

The electrochemistry of benzoquinone/hydroquinone redox couple in both aqueous $\mathrm{s}^{2,3,5,7}$ and nonaqueous $\mathrm{s}^{4,6,8}$ mediums has been the subject of numerous investigations. In an aqueous medium, the general reaction scheme known as a scheme of

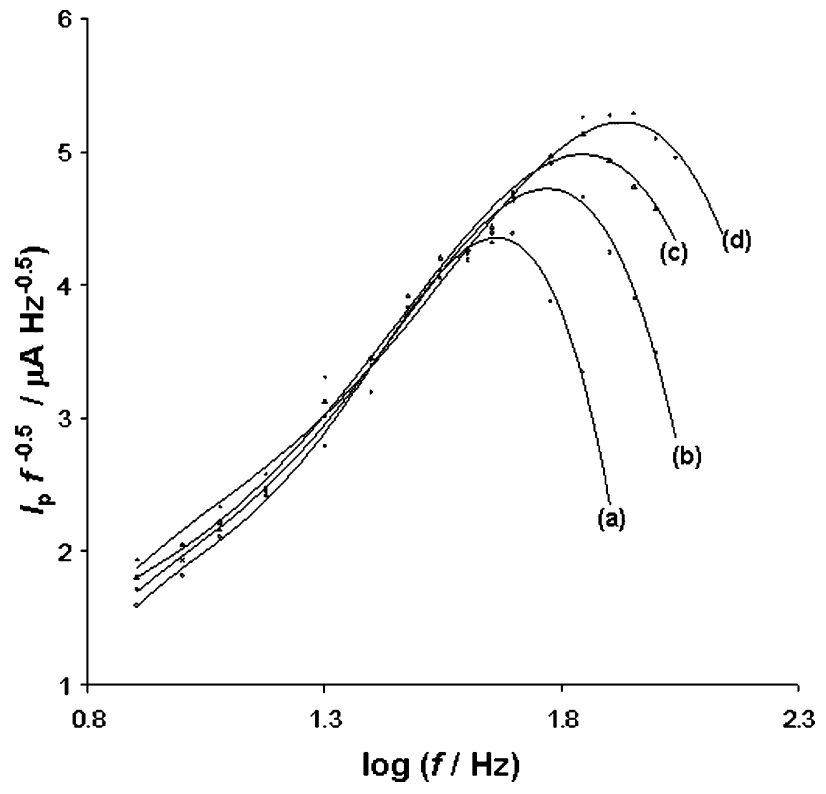

Figure 9. Quasireversible maxima corresponding to the redox process I recorded in contact with an aqueous solution at $\mathrm{pH}$ of 3.9 containing $\mathrm{ClO}_{4}{ }^{-}$at a concentration of 0.9 (a), 10 (b), 30 (c), and $100 \mathrm{mmol} / \mathrm{L}$ (d). Parameters of the potential modulation were $E_{\mathrm{sw}}=50 \mathrm{mV}$ and $\mathrm{d} E$ $=1 \mathrm{mV}$. The other conditions are the same as for Figure 3 .
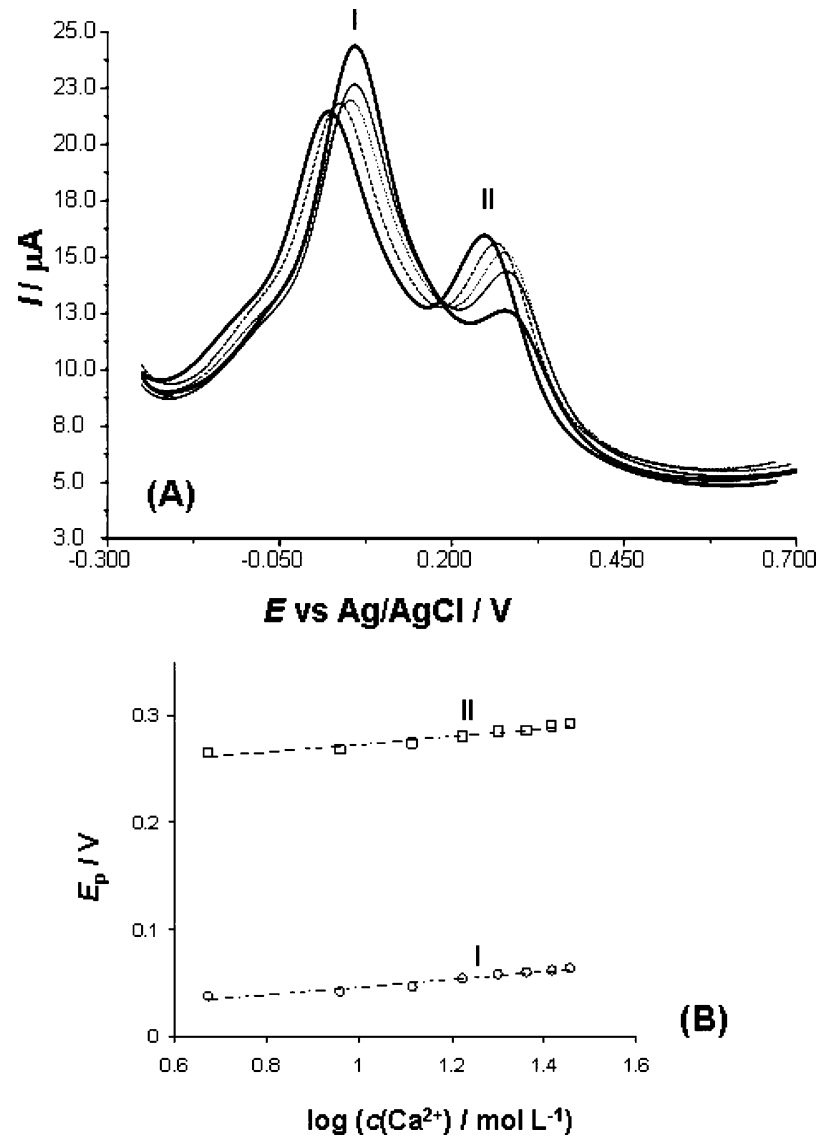

(B)

Figure 10. (A) SW voltammograms of thin-film electrode recorded in the presence of $\mathrm{Ca}^{2+}$ with the aqueous solution buffered to $\mathrm{pH}$ 3.9. The concentration of $\mathrm{Ca}^{2+}$ was $0,5.8,11.1,15.3$, and $19 \mathrm{mmol} / \mathrm{L}$ (from left toward right). The other conditions were same as for Figure 3. (B) Dependence of the peak potentials $E_{\mathrm{p}}$ on the $\log \left(\mathrm{Ca}^{2+}\right)$ for both voltammetric peaks.

squares is particularly complicated, including six possible redox transformations coupled to six protonation reactions. Nevertheless, in an aqueous media the redox transformation most 

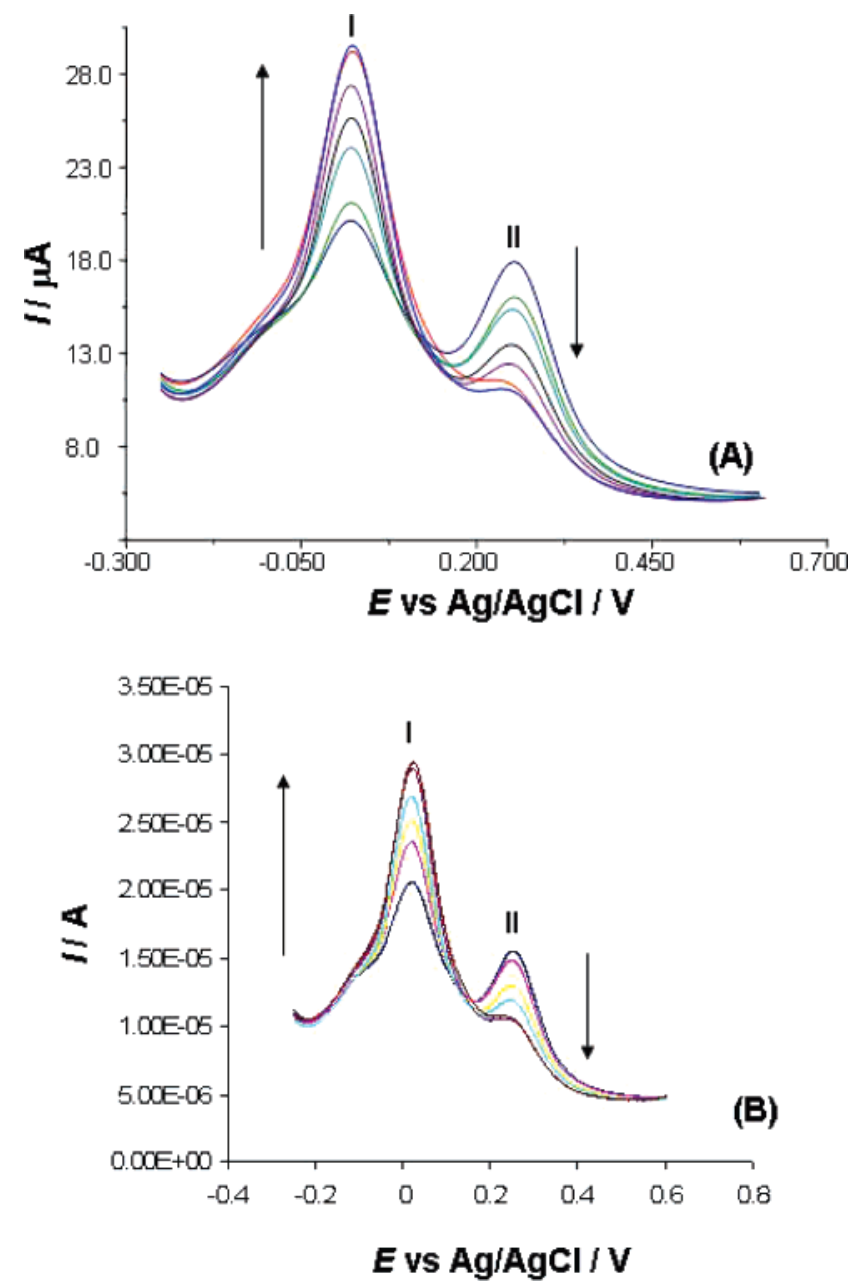

Figure 11. (A) Consecutive net SW voltammograms recorded in contact with aqueous medium at $\mathrm{pH} 3.9$ containing $5.8 \mathrm{mmol} / \mathrm{L} \mathrm{Ca}^{2+}$. (B) Effect of the incubation time of the electrode in a separate aqueous solution containing $0.1 \mathrm{~mol} / \mathrm{L} \mathrm{Ca}^{2+}$ ions. The incubation time increases in the direction of the arrows from 3, 7, 13, 21, 35, and 45 min. After incubation period, the electrode was transferred into a $\mathrm{Ca}^{2+}$-free aqueous solution at $\mathrm{pH}$ 5.8. The other conditions are the same as in Figure 5.

frequently appears as a quasireversible one step, coupled twoelectron-two-proton $\left(2 \mathrm{e} / 2 \mathrm{H}^{+}\right)$process. $^{2}$ On the contrary, in a nonaqueous media, two energetically distinctive reversible oneelectron redox steps have been observed with voltammetric techniques, mediated by formation of a semiquinone form. ${ }^{2,3}$

The overall voltammetric behavior of the studied compound strongly deviates from the common behavior of the benzoquinone/hydroquinone redox couple. ${ }^{23}$ Voltammetric curves recorded under a variety of conditions feature two distinctive oxidative processes with strongly different voltammetric characteristics. The two processes are not exclusively observed in the thin organic-film membrane experiment, but they are equally present in the experiments conducted in direct contact with the aqueous phase. At a slow scan rate, the voltammetric features of the oxidative process I are close to the reversible behavior typical for a two-electron process (cf. Figure 5a). Taking the linear dependence on $\mathrm{pH}$ with a slope of $-60 \mathrm{mV} / \mathrm{pH}$ into account, it follows that the oxidative process I involves overall $2 \mathrm{e} / 2 \mathrm{H}^{+}$exchange, which is typical for benzoquinone/hydroquinone redox couple. On the contrary, the process II exhibits typical characteristics of a CE reaction scheme in which the electroactive reactant is supplied by a preceding chemical reaction. This is confirmed by varying the scan rate in $\mathrm{CV}$ and
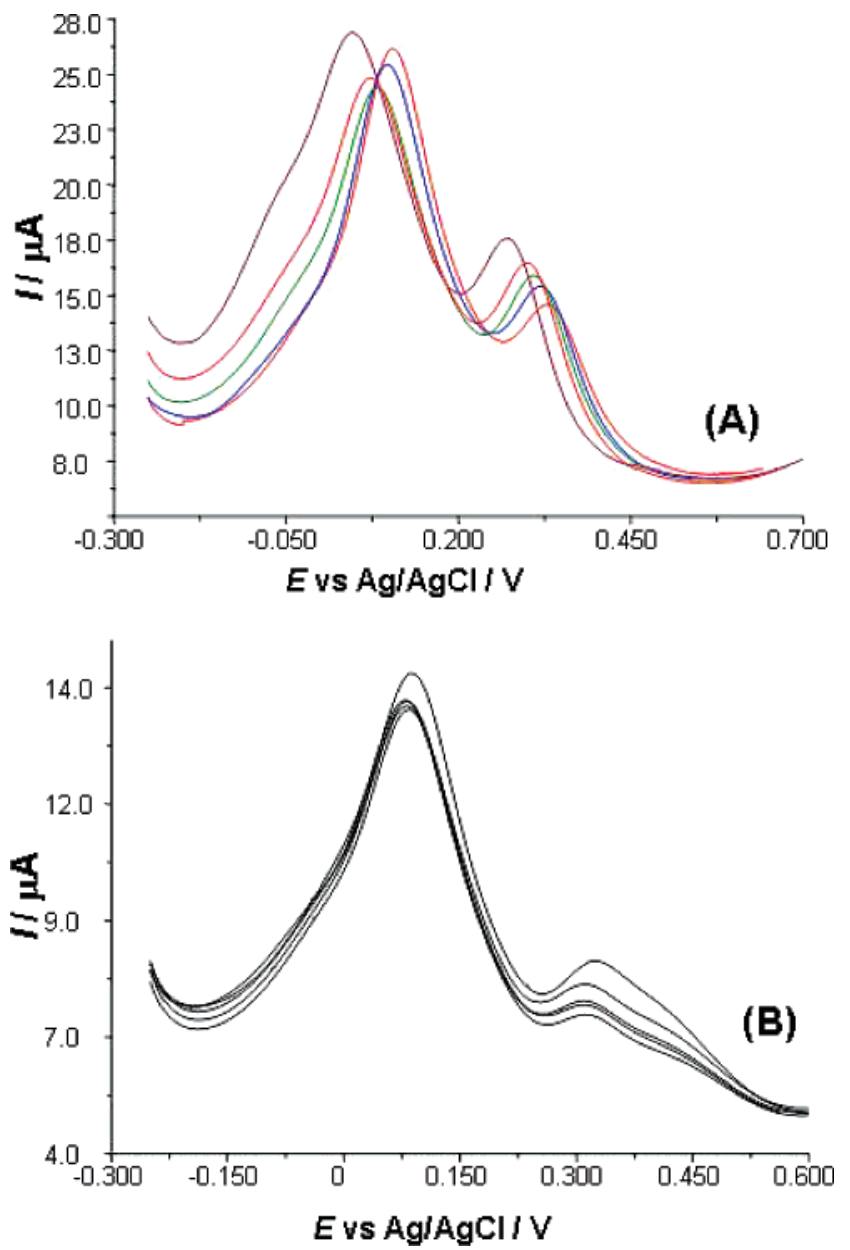

Figure 12. $\mathrm{SW}$ voltammograms recorded in the presence of $\mathrm{Mg}^{2+}(\mathrm{A})$ and $\mathrm{Ba}^{2+}(\mathrm{B})$ ions in the aqueous phase at $\mathrm{pH}$ 5.0. For (A), the concentration of $\mathrm{Mg}^{2+}$ was $0,10,20,30$, and $40 \mathrm{mmol} / \mathrm{L}$ (from left to right). For (B), the concentration of $\mathrm{Ba}^{2+}$ was $0,4.7,9.3,13.1$, and 17 $\mathrm{mmol} / \mathrm{L}$. Parameters of the potential modulation were $f=8 \mathrm{~Hz}, E_{\mathrm{sw}}=$ $50 \mathrm{mV}$, and $\mathrm{d} E=1 \mathrm{mV}$. The other conditions are the same as for Figure 3.

frequency in SWV for both types of experimental arrangements (cf. Figures $5 \mathrm{c}$ and $8 \mathrm{~B}$ ). Moreover, the results presented in Figure 7 show that the electroactive reactant for the oxidative process II is not generated in the previous electrochemical process I. This excludes the possibility to explain the two oxidative processes on the basis of two one-electron consecutive processes with a formation of a stable semiquinone radical. Furthermore, a careful inspection of the voltammetric curves in Figure 7 reveals that the current due to the second oxidative process II slightly decreases with time. Therefore, the two electrochemical processes originate from redox transformations of two distinctive redox forms of $\mathrm{H}_{2} \mathrm{Q}$ molecule. The interrelation of the peak magnitudes implies that the two redox forms are interconnected by a chemical equilibrium reaction. Over a variety of experimental conditions, the sum of the two oxidative peaks is constant and proportional to the total concentration of $\mathrm{H}_{2} \mathrm{Q}$.

Considering the molecular structure of $\mathrm{H}_{2} \mathrm{Q}$ (Figure 1), it is reasonable to assume that the intriguing voltammetric characteristic of the present compound originates from the influence of palmitoyl residue in the position 2 of the hydroquinone ring. The carbonyl group in the position 2 can establish a tautomerism equilibrium with the adjacent hydroxyl group from the hydroquinone ring as follows: ${ }^{24}$ 


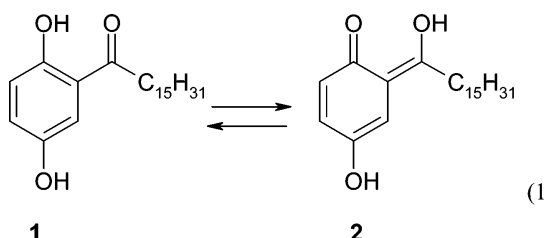

Both tautomers $\mathbf{1}$ and $\mathbf{2}$ can undergo independent redox transformation to yield a quinone form according to the following schemes:

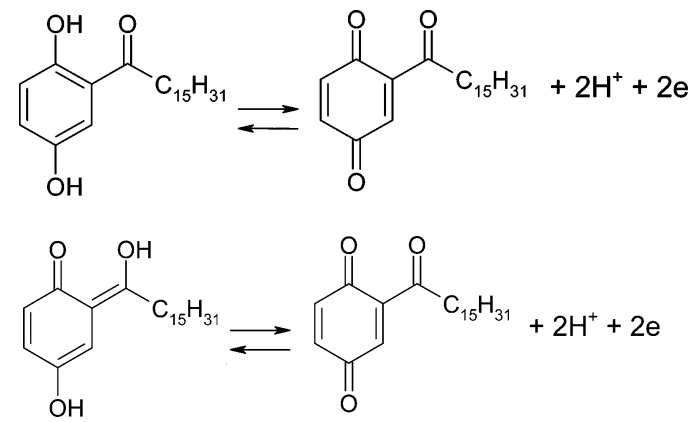

Reaction 2 is the common redox transformation of the hydroquinone/benzoquinone redox couple involving an overall $2 \mathrm{e} / 2 \mathrm{H}^{+}$exchange, assigned to the oxidation process I. The equilibrium chemical reaction (1), coupled to the redox reaction (3), completes a $\mathrm{CE}$ reaction scheme thus being attributed to the oxidation process II.

The position of the tautomerism equilibrium 1 depends critically on the $\mathrm{pH}$ of the medium, being shifted toward the form 2 by decreasing $\mathrm{pH}$, which agrees with the known acidic catalysis of the keton-enol transformation. ${ }^{25}$ For these reasons, the ratio of the anodic peak currents $I_{\mathrm{p}, \mathrm{a}}(\mathrm{I}) / I_{\mathrm{p}, \mathrm{a}}(\mathrm{II})$ increases with increasing $\mathrm{pH}$ (cf. Figure 4). The kinetics of the tautomer transformation is apparently a slow process, which causes a decrease of the net SW peak II by enhancing the SW frequency, as shown in Figure 8B. For the same reasons, the ratio $I_{\mathrm{p}, \mathrm{a}}(\mathrm{II}) / v$ decreases (cf. Figure 5c), whereas the anodic peak current ratio $I_{\mathrm{p}, \mathrm{a}}(\mathrm{I}) / I_{\mathrm{p}, \mathrm{a}}(\mathrm{II})$ increases (cf. Figure $5 \mathrm{~b}$ ) with an increased scan rate of the $\mathrm{CV}$ experiment. In addition, as can be inferred from the results in Figure 5, the redox reaction (3) is an electrochemically irreversible process. The kinetics of the reduction of the quinone form back to the tautomer form $\mathbf{2}$ are very low, depending critically on the $\mathrm{pH}$ of the medium. Accordingly, the increase of either the $\mathrm{pH}$ or the scan rate in a $\mathrm{CV}$ experiment caused the reduction peak II' to shift strongly toward negative potentials. Obviously, at $\mathrm{pH} \geq 5.5$ and $v \geq 100 \mathrm{mV} / \mathrm{s}$ the reduction of quinone form yields mainly tautomer $\mathbf{1}$ (cf. Figures 4 and 5).

The slow establishment of the tautomer equilibrium explains the evolution of the SW voltammograms under the repetitive cycling of the SW potential modulation (cf. Figure 6A). During a SW potential scan, a part of both $\mathbf{1}$ and $\mathbf{2}$ forms of the previously established equilibrium is consumed, resulting in formation of the quinone form. Switching the potential to the initial value (i.e., $-0.25 \mathrm{~V}$ ) the form $\mathbf{1}$ is mainly generated without having sufficient time to re-establish the equilibrium 1. As a consequence, the oxidation peak I increases at the expense of the peak II. If the electrode was kept for a certain period in contact with the aqueous solution under open circuit conditions or at the initial potential value, the contact time had no effect on the shape of voltammograms, as the position of the tautomerism equilibrium was predominantly fixed by the $\mathrm{pH}$ of the medium (cf. Figure 6B).
The kinetic measurements conducted with QRM for both experimental configurations showed that the apparent rate of the reaction 2 increased by decreasing the $\mathrm{pH}$, agreeing with theoretical predictions for this type of redox processes. ${ }^{2,23}$ For the thin-film experiment, the situation is particularly complex as the $2 \mathrm{e} / 2 \mathrm{H}^{+}$redox transformation in the membrane must be accompanied by a corresponding ion-transfer reaction across the membrane/water interface to maintain the charge neutrality of the membrane. If the proton expulsion is the chargecompensating ion-transfer reaction, the reaction 2 should be written as follows:

$$
\mathrm{H}_{2} \mathrm{Q}_{(\mathrm{nb})} \rightleftarrows \mathrm{Q}_{(\mathrm{nb})}+2 \mathrm{H}_{(\mathrm{w})}^{+}+2 \mathrm{e}
$$

This overall reaction comprises the $2 \mathrm{e} / 2 \mathrm{H}^{+}$redox transformation in the membrane and the expulsion of protons into the aqueous phase. It should be taken into account that water-saturated NB contains $0.2 \mathrm{~mol} / \mathrm{L}$ water. Thus, it is plausible to assume that the protons can be accepted by the water molecules, and the charge neutrality of the membrane can be maintained by ingress of aqueous $\mathrm{ClO}_{4}^{-}$ions, which are present in a large excess in both liquid phases. Hence, the reaction 2 can be written as:

$$
\mathrm{H}_{2} \mathrm{Q}_{(\mathrm{nb})}+2 \mathrm{ClO}_{4}^{-}{ }_{(\mathrm{w})} \rightleftarrows \mathrm{Q}_{(\mathrm{nb})}+2 \mathrm{H}_{(\mathrm{nb})}^{+}+2 \mathrm{ClO}_{4}^{-}(\mathrm{nb})+\underset{(5)}{2 \mathrm{e}}
$$

Taking into account the standard Gibbs energy for the transfer from water into $\mathrm{NB}$ of $\mathrm{ClO}_{4}{ }^{-}$and $\mathrm{H}^{+}$(i.e., $\Delta^{\mathrm{w} \rightarrow \mathrm{nb}} G_{\mathrm{ClO}_{\mathrm{O}^{-}}}^{\theta}=7.4$ $\mathrm{kJ} \mathrm{mol}^{-1}$ and $\left.\Delta^{\mathrm{w} \rightarrow \mathrm{nb}} G_{\mathrm{H}+}^{\theta}=32.5 \mathrm{~kJ} \mathrm{~mol}^{-1}\right),{ }^{26}$ the expulsion of protons from NB membrane is the thermodinamically favored process.

Kinetic measurements performed with QRM showed that the electrochemical process I was accelerated by increasing the concentration of the $\mathrm{ClO}_{4}{ }^{-}$ion in the aqueous phase (cf. Figure 9). Recall that the Galvani potential difference at the membrane/ water interface $\left(\Delta \phi_{\mathrm{w}}^{\mathrm{o}}\right)\left(\Delta \phi_{\mathrm{w}}^{\mathrm{o}}=\phi_{\mathrm{o}}-\phi_{\mathrm{w}} ; \phi_{\mathrm{o}}\right.$ and $\phi_{\mathrm{w}}$ are the inner potential of the membrane and aqueous phase, respectively) is defined as follows:

$$
\Delta \phi_{\mathrm{w}}^{\mathrm{o}}=\Delta^{\mathrm{w}} \rightarrow^{\mathrm{o}} \phi_{\mathrm{ClO}_{4^{-}}}^{\theta}+\frac{R T}{F} \ln \frac{\left[\mathrm{ClO}_{4}^{-}\right]_{\mathrm{o}}}{\left[\mathrm{ClO}_{4}^{-}\right]_{\mathrm{w}}}
$$

Here $\Delta^{\mathrm{w} \rightarrow \mathrm{o}} \phi_{\mathrm{ClO}_{4}}^{\theta}$ is the standard transfer potential of $\mathrm{ClO}_{4}{ }^{-}$ from water to $\mathrm{NB}$, and $\left[\mathrm{ClO}_{4}^{-}\right]$designates the equilibrium concentration. In addition, the partition concentration of protons in the organic phase depends on $\Delta \phi_{\mathrm{w}}^{\mathrm{o}}$ as follows:

$$
\left[\mathrm{H}^{+}\right]_{\mathrm{o}}=\left[\mathrm{H}^{+}\right]_{\mathrm{w}} \exp \left[-\frac{F}{R T}\left(\Delta \phi_{\mathrm{w}}^{\mathrm{o}}-\Delta^{\mathrm{w} \rightarrow \mathrm{o}} \phi_{\mathrm{H}^{+}}^{\theta}\right)\right]
$$

where $\Delta^{\mathrm{w} \rightarrow \mathrm{o}} \phi_{\mathrm{H}^{+}}^{\theta}$ is the standard transfer potential of $\mathrm{H}^{+}$. For $\left[\mathrm{ClO}_{4}^{-}\right]_{\mathrm{o}}=0.1 \mathrm{~mol} / \mathrm{L}$, increasing $\left[\mathrm{ClO}_{4}{ }^{-}\right]_{\mathrm{w}}$ from 0.01 to 0.1 $\mathrm{mol} / \mathrm{L}$, as in Figure 9 , caused $\Delta \phi_{\mathrm{w}}^{\mathrm{o}}$ to change from 137 to 80 $\mathrm{mV}$, thereby enhancing the concentration of protons in the organic phase. This can finally cause an increase in the rate of the $2 \mathrm{e} / 2 \mathrm{H}^{+}$redox transformation in the membrane. Thus, the conclusion of whether the redox transformation in the membrane or the proton expulsion is the rate-limiting step is not straightforward.

Results presented in Figures 10 and 11 reveal the binding affinity of $\mathrm{H}_{2} \mathrm{Q}$ toward $\mathrm{Ca}^{2+}$ through an interfacial complexation reaction at the membrane/water interface. The consistent shift of both peaks I and II as a function of the $\mathrm{Ca}^{2+}$ concentration implies that both redox forms $\mathbf{1}$ and $\mathbf{2}$ are involved in the interfacial complexation (cf. Figure 10A), resulting in assisted 
transfer of $\mathrm{Ca}^{2+}$ ions in the membrane interior. Upon oxidation, $\mathrm{Ca}^{2+}$ ions are expelled out of the membrane. Both peak potentials shift equally with $\log \left[\mathrm{Ca}^{2+}\right]$ (cf. Figure 10B) and with a slope of about $30 \mathrm{mV}$, indicating formation of a complex with 1:1 stoichiometry. This is in agreement with the results of Bennet et al. who reported the stability constants of 820 and $75 \mathrm{~mol}^{-1} \mathrm{~L}$ for the complexes of one $\mathrm{Ca}^{2+}$ ion with one or two $\mathrm{HQ}^{-}$ions, respectively. ${ }^{10}$ The electrochemical reaction in the presence of $\mathrm{Ca}^{2+}$ ions can be represented by the following scheme:

$$
\begin{aligned}
& \mathrm{CaHQ}_{(\mathrm{nb})}^{+}+\mathrm{ClO}_{4}^{-}(\mathrm{nb}) \rightleftarrows \mathrm{Q}_{(\mathrm{nb})}+\mathrm{Ca}^{2+}{ }_{(\mathrm{w})}+\mathrm{H}_{(\mathrm{w})}^{+}+ \\
& \mathrm{ClO}_{4}^{-}(\mathrm{w})+2 \mathrm{e}
\end{aligned}
$$

This equation clearly explains why the $\mathrm{pH}$ dependence of the peak potential is switched from -60 to $-30 \mathrm{mV} / \mathrm{pH}$ in the absence and presence of $\mathrm{Ca}^{2+}$ ions, respectively.

The formation of the $\mathrm{Ca}^{2+}$ complex by engaging the two adjacent oxygen atoms of $\mathrm{H}_{2} \mathrm{Q}$ molecule expels the proton (or protons) that is involved in the tautomerism equilibrium 1 , thus preventing formation of the $\mathbf{2}$ form. As a consequence, in the presence of $\mathrm{Ca}^{2+}$ the equilibrium 1 is shifted strongly toward the form 1, causing a substantial increase of the peak I over the peak II. This can be achieved by either subsequent cycling of the potential (cf. Figure 11A) or incubation of the electrode in the $\mathrm{Ca}^{2+}$-containing solution under open circuit conditions (cf. Figure 11B).

The overall voltammetric behavior in the presence of $\mathrm{Mg}^{2+}$ (Figure 12A) is equivalent to that in the presence of $\mathrm{Ca}^{2+}$ ions, revealing that $\mathrm{H}_{2} \mathrm{Q}$ does not discriminate between $\mathrm{Ca}^{2+}$ and $\mathrm{Mg}^{2+}$ ions. On the contrary, the voltammetric response is insensitive to $\mathrm{Ba}^{2+}$ (Figure 12B), showing the absence of complexing ability of $\mathrm{H}_{2} \mathrm{Q}$ toward these ions that could be rationalized by taking the larger ionic radius of $\mathrm{Ba}^{2+}$ into account, which does not fit with the distance between the oxygen atoms participating in the complexation.

\section{Conclusion}

Controlling $\mathrm{pH}$ and $\mathrm{Ca}^{2+}$ concentrations within a certain range in the intra- and extracellular space of the human body are necessary for the proper function of all organs. Because organic compounds containing a benzoquinone/hydroquinone moiety are highly relevant for many physiological functions, we analyzed their redox, binding, and transport properties. Using SWV and $\mathrm{CV}$, we found that $\mathrm{H}_{2} \mathrm{Q}$ can be oxidized to a quinone form through $2 \mathrm{e} / 2 \mathrm{H}^{+}$redox pathway coupled by expulsion of protons out of the interior of the membrane. $\mathrm{H}_{2} \mathrm{Q}$ undergoes two distinct oxidation processes with either yielding a quinone form. The two redox processes are assigned to two tautomer forms of $\mathrm{H}_{2} \mathrm{Q}$ formed by migration of a proton between the hydroxyl group in the position 1 of the hydroquinone ring and the adjacent carbonyl group of the palmitoyl residue.

Taking further advantage of the quantitative and kinetic aspects of the data analysis, we could show how $\mathrm{Ca}^{2+}$ and proton binding and their transport by the quinone/hydroquinone system interact with each other. The $\mathrm{Ca}^{2+}$ transport was found to be clearly $\mathrm{pH}$ dependent. The stoichiometry for $\mathrm{Ca}^{2+} / \mathrm{HQ}^{-}$is $1: 1$. Upon oxidation of the $\mathrm{Ca}^{2+}-\mathrm{H}_{2} \mathrm{Q}$ complex in the membrane, $\mathrm{Ca}^{2+}$ together with one proton are expelled out of the membrane. Whereas binding and transfer across membrane/water interface were found to be similar for $\mathrm{Mg}^{2+}, \mathrm{Ba}^{2+}$ did not affect the voltammetric response. This indicates that the studied compound does not discriminate between $\mathrm{Ca}^{2+}$ and $\mathrm{Mg}^{2+}$, the two physiologically relevant divalent cations, but can discriminate against other cations.

Acknowledgment. This work was supported by the Deutsche Forschungsgemeinschaft (SFB 530, project A3 and Graduate College 845 "Molecular, physiological, and pharmacological analysis of cellular membrane transport") and HOMFOR. V.M. acknowledges gratefully the financial support of A. v. Humboldt-Stiftung. R.G. thanks the Fundacao para a Ciencia e a Tecnologia (FCT) of Portugal for providing of a postdoctoral fellowship (SFRH/BPD/14894/2004).

\section{References and Notes}

(1) Dallner, G.; Sindelar, P. J. Free Radical Biol. Med. 2000, 29, 285.

(2) Laviron, E. J. Electroanal. Chem. 1984, 164, 213.

(3) (a) Gordillo, C. J.; Schiffrin, D. J. Faraday Discuss. 2000, 116, 89. (b) Moncelli, M. R.; Becucci, L.; Nelson, A.; Guidelli, R. Biophys. J. 1996, $70,2716$.

(4) Gordillo, C. J.; Schiffrin, D. J. J. Chem. Soc., Faraday Trans. 1994, 90, 1913.

(5) Sek, S.; Bilewicz, R. J. Inclusion Phenom. Macrocyclic Chem. 1999, $35,55$.

(6) Mulkidjanian, A. Y.; Cherepanov, D. A.; Heberle, J.; Junge, W. Biochemistry 2005, 70, 251.

(7) Eckert, T. S.; Bruice, T. C.; Gainor, J. A.; Weinreb, S. M. Proc. Natl. Acad. Sci. U.S.A. 1982, 79, 2533.

(8) Itos, S.; Kawakami, H.; Fukuzumi, S. J. Am. Chem. Soc. 1998 , 120,7271 .

(9) Zhou, J.; Felderhoff, M.; Smelkova, N.; Gornastaev, L. M.; Rieker, A. J. Chem. Soc., Perkin Trans. 1998, 2, 343.

(10) Bennett, I. M.; Vanegas Farfano, H. M.; Bogani, F.; Primak, A.; Liddell, P. A.; Otero, L.; Sereno, L.; Silber, J. J.; Moore, A. L.; Moore, T. A.; Gust, D. Nature 2002, 420, 398

(11) Quintana, A.; Griesemer, D.; Schwarz, E. C.; Hoth, M. Pflugers Arch. 2005, 450, 1 .

(12) Chung, T. D.; Anson, F. C. Anal. Chem. 2001, 73, 337.

(13) Shi, C. N.; Anson, F. C. Anal. Chem. 1998, 70, 3114.

(14) Shi, C. N.; Anson, F. C. J. Phys. Chem. B 1998, 102, 9850.

(15) Scholz, F.; Gulaboski, R. ChemPhysChem 2005, 6, 16.

(16) Mirčeski, V.; Quentel, F.; L'Her, M.; Pondaven, A. Electrochem. Commun. 2005, 7, 1122 .

(17) Mirčeski, V.; Quentel, F.; L’Her, M.; Scholz, F. J. Electroanal. Chem. 2006, 586, 86.

(18) Gulaboski, R.; Mirčeski, V.; Pereira, C. M.; Cordeiro, M. N. D. S.; Silva, A. F.; Quentel, F.; L'Her, M.; Lovrić, M. Langmuir 2006, 22, 3404.

(19) Marken, F.; Neudeck, A.; Bond, A. M. Cyclic Voltammetry. In Electroanalytical Methods; Scholz, F., Ed.; Springer: Berlin, 2001; pp 5097.

(20) Lovric, M. Square-Wave Voltammetry. In Electroanalytical Methods; Scholz, F., Ed.; Springer: Berlin, 2001; p 111.

(21) Mirčeski, V. J. Phys. Chem. B 2004, 108, 13719.

(22) Quentel, F.; Mirčeski, V.; L’Her, M. Anal. Chem. 2005, 77, 1940.

(23) Laviron, E. J. Electroanal. Chem. 1984, 164, 213.

37.

(24), Y.; Duan, J.; Qi, X.; Chen, G. Bioelectrochemistry 2003, 60 ,

(25) Vollhardt, K. P. C.; Schore N. E. Organische Chemie, 3rd edition; Wiley: Weinheim, 2000; pp 843-846.

(26) ElectroChemical Data Base. http://lepa.epfl.ch/. 